\title{
Derecho de propiedad privada y fiscalidad en Francisco Suárez
}

The right of private property and taxation in Francisco Suárez

FERnando Hernández Fradejas

Universidad de Valladolid

Departamento de Derecho Penal e Historia y Teoría del Derecho

Facultad de Derecho

47002 Valladolid (España)

fernando.hernandez.fradejas@uva.es

Abstract: This paper analyzes the economic ideas of Francisco Suárez. Although the relevant passages are scattered throughout his work, it can be shown that Suárez addressed the right of private property. In addition, Suárez examined fiscal issues in the book $\checkmark$ of the treaty De legibus ac Deo legislatore. These are two of the least explored topics in Suárez's legal philosophy.

Keywords: Private property right, goods division, taxation, imposition, Francisco Suárez.
Resumen: Este artículo analiza las ideas económicas de Francisco Suárez. Por una parte, el Doctor Eximio estudió el derecho de propiedad privada a pesar de la dispersión de los materiales en su obra. Y, por otra parte, Suárez examinó la cuestión fiscal en el libro $V$ del tratado De legibus ac Deo legislatore. Éstos son dos de los temas menos explorados de la filosofía jurídica suareciana.

Palabras clave: Derecho de propiedad privada, división de los bienes, fiscalidad, tributación, Francisco Suárez. 


\section{INTRODUCCIÓN}

L lobjetivo de esta investigación es doble: en primer lugar, analizar la institución del Derecho de propiedad privada y, en segundo lugar, examinar el tratamiento en materia fiscal en la obra de Francisco Suárez. El artículo, desde el subtítulo segundo, explora el concepto de derecho de propiedad privada, discutiendo la naturaleza de la misma desde la primera subdivisión, bien se incluya en el Derecho natural, Derecho de gentes o Derecho positivo. Las dos posteriores subdivisiones del subtítulo segundo ofrecen, por un lado, una triple clasificación respecto al derecho de propiedad (dominio, propiedad privada y dominio-propiedad) y, por otro lado, la tesis de que la naturaleza del Derecho de propiedad privada - $\mathrm{O}$ división de los bienes - es de Derecho de gentes y no puede contradecir el Derecho natural, ya que la finalidad de la división de los bienes es ocuparse de las necesidades de todos los hombres. A continuación, en el subtítulo tercero, se examina las ideas tributarias en Francisco Suárez de acuerdo con el tomo V de la obra Tractatus de Legibus ac Deo Legislatore. Además se añaden tres subdivisiones a este subtítulo: las tres condiciones de la justicia tributaria, el rechazo del antiguo derecho de Hispania sobre la imposición de tributos y la polémica en torno a la obligación y reclamación del pago de impuestos según el pensamiento suareciano. Esta aportación académica, por tanto, desea cubrir una de las principales lagunas dentro del pensamiento económico del erudito Francisco Suárez.

\section{EL DERECHO DE PROPIEDAD PRIVADA EN FRANCISCO SUÁREZ}

Quizás una de las grandes aportaciones del jesuita Francisco Suárez S.J. (1548-1617) a la teoría económica sea la consolidación de la teoría activa de los derechos naturales aplicada a la propiedad privada $^{1}$, cuyos antecedentes principales se encuentran en la ciencia

1. M. Calvillo, Francisco Suárez: La filosofía jurídica. El derecho de propiedad, 43 (El Colegio de México, México, 1945) 31-114; R. Sierra Bravo, El pensamiento social y económico de la escolástica. Desde sus orígenes al comienzo del catolicismo social, t. I (Consejo Superior de Investigaciones Científicas, Madrid, 1975) 129-141. 
jurídica romana ${ }^{2}$, en el Ius Commune ${ }^{3}$, en la obra Summa Theologica de Santo Tomás de Aquino (1225-1274) y, al mismo tiempo, en los Comentarios a la Secunda Secundae de Santo Tomás ${ }^{5}$ del maestro fraile dominico Francisco de Vitoria (1483-1546). Aunque la filosofía jurídica suareciana no exploró el concepto de propiedad privada de modo sistemático en un principio ${ }^{6}$, sí se conserva cierto manuscrito de sus lecciones en el Colegio Romano de los Jesuitas las cuales han sido publicadas con el título de Quaestiones de iustitia et iure a mediados del siglo XX ${ }^{7}$. De tal modo, el jesuita Francisco Suárez, junto con otros miembros de la denominada Escuela de Salamanca ${ }^{8}$, meditaron cuál ha sido la relación entre la existencia histórica del derecho de propiedad privada y el principio filosófico-moral-religioso

2. R. V. Ihering, El espíritu del derecho romano (Marcial Pons, Madrid, 1997); H. CoING, Derecho Privado Europeo: Derecho Común más antiguo (1500-1800), t. I (Fundación Cultural Notariado, Madrid, 1996) y Á. D’Ors, Derecho privado romano (Eunsa, Pamplona, 2004).

3. A. PÉrez MarTín, El ius commune: artificio de juristas, en T. DE Montagut (ed.), Història del pensament jurídic: curs 1996-97 dedicat a la memòria del professor Francisco Tomás y Valiente (Universitat Pompeu Fabra, Barcelona, 1999) 69-93.

4. T. DE AQUINO, Suma teológica, vols. 80-81 (BAC, Madrid, 1955-1956) II-II, q. 66, a. 1 citado en F. GÓMEZ CAMACHO, Economía y filosofía moral: la formación del pensamiento económico europeo en la Escolástica española (Síntesis, Madrid, 1998) cap. 3,88 .

5. F. DE VITORIA, Comentarios a la Secunda Secundae de Santo Tomás (Edt. V. Beltrán de Heredia, Salamanca, 1932-1935) q. 62, a. 1 citado en F. Gómez CAMACHO, Economía y filosofía moral cit., cap. 3, 88 .

6. Antonio Ferreiro López indica que "es cierto que él no escribió el tratado De fustitia et fure donde otros autores estudian ampliamente la materia que nos ocupa. Pero, [...], la mayor parte de estas materias las tocó Suárez en otros puntos", véase en A. FERREIRo LóPEZ, La naturaleza de la propiedad privada en las doctrinas de Suárez, "Pensamiento" 4 (1948) 450. Estos puntos requieren una labor de búsqueda de materiales en obras dispersas (De legibus ac Deo legislatore, Defensio fidei christianae adversus anglicanae sectae errores, De opere sex dierum, De virtute et statu religionis, De fide, spe et charitate, De mysteriis vitae Christi).

7. J. GIERS, Die Gerechtigkeitslebre des jungen Suárez (Freiburg, Herder, 1958) 12-21 citado en A. GuZMán BRITO, El derecho como facultad en la neoescolástica del siglo XVI (Iustel, Madrid, 2009) 200. Incluso más, el Profesor Guzmán Brito declara que "su contenido viene atribuido, en efecto, a Suárez en el manuscrito mismo y acerca de la atribución no hay razones para dudar".

8. A este respecto, resulta interesante distinguir las diferentes opiniones del término por los profesores Pedro Schwartz, Marjorie Grice-Hutchinson, Alejandro Chafuén, Oreste Popescu, José Barrientos, Luis Perdices de Blas, Julio Revuelta, Luciano Pereña, Francisco Gómez Camacho o Mark Blaug. 
que reconoce el régimen común de la propiedad en la etapa de la humanidad anterior al pecado original. El resultado de este debate es doble: por un lado, un modelo social basado en el respeto de la propiedad privada y, por otro lado, un modelo social fundado en la propiedad común.

\section{El derecho de propiedad en Francisco Suárez: \\ ¿Derecho natural o derecho de gentes?}

La naturaleza del Derecho de propiedad privada ${ }^{9}$ es una de las controversias centrales del campo jurídico. La clasificación de este Derecho tiene unas consecuencias transcendentales, bien se encuadre en el Derecho natural ${ }^{10}$ o en el Derecho de gentes o en el Derecho positivo $^{11}$. El primer concepto entiende el Derecho de propiedad privada como una característica esencial que forma parte de la naturaleza del ser humano, de carácter inmutable y permanente; por el contrario, el Derecho de gentes o positivo comprende el Derecho de propiedad privada como un hecho eventual, arbitrario o tan sólo contingente según las circunstancias concretas de tiempo y lugar. Ambas interpretaciones fundamentan sus posturas teóricas con los grandes maestros de la Teología, aunque algunos estudiosos, como A. Ferreiro López, señalan la carencia de un estudio sistemático, formalizado y profundo sobre este tema ${ }^{12}$. De manera concreta, Suárez ${ }^{13}$ trata el concepto de Derecho Natural en dos libros distintos de su obra De Legibus: libro II, capítulos V-XVII y en el libro I, capítulo III. Este autor expone varias definiciones de su concepto

9. Véase el completo y erudito trabajo de F. T. BACIERo RuIZ, Derecho de propiedad y derecho subjetivo en Francisco Suárez y Locke, "Anuario Filosófico" 45/2 (2012) 403408.

10. H. A. Rommen, The natural law: A study in legal and social bistory and philosophy (Liberty Fund, Indianapolis, 1998) 30-61.

11. Para esta subdivisión, seguiremos la obra del antiguo Canónigo Magistral de Jaén A. Ferreiro López, op. cit., 449-460, docto estudio acerca del Derecho de propiedad en Francisco Suárez.

12. Ibidem, 450-451.

13. J. M. Palacio, Naturaleza del derecho de propiedad, "Ciencia Tomista" 52 (1935) 348. 
de derecho natural en varios de los puntos del capítulo III de este libro. La primera de ellas sostiene "que se llama [ley] natural de alguna manera todo aquello que ha sido creado junto con la naturaleza y que siempre se ha conservado en ella"14; la segunda definición apunta que la ley [o Derecho] natural es "aquella que ha nacido en el hombre juntamente con la naturaleza" 15 ; en este mismo sentido, Suárez da otra definición de derecho natural como aquello que "procede de Dios por medio de la naturaleza, de la cual dimana como una propiedad suya" 16 . También señala otros rasgos del Derecho Natural como "una propiedad intrínseca que fluye necesariamente de la naturaleza racional en cuanto tal" 17 y "que se sigue no de la esencia particular de un individuo sino de la naturaleza específica, la cual es la misma en todos"18. Por su parte, el objeto del Derecho Natural de Suárez refuerza el contenido de las definiciones de Derecho natural mencionadas detrás. Argumenta que la materia u objeto de esta ley [Derecho natural] "son el bien honesto de suyo o necesario para la honestidad"19 y "comprende todos los preceptos o principios morales que tienen una evidente honestidad tan necesaria para la rectitud moral"20. Según su obra De Legibus, la confirmación de esta tesis se explica a través de la razón mediante tres clases $^{21}$ : los principios morales generales, los principios más determinados y particulares y, por último, las conclusiones. Parece evidente que la tesis final de Suárez queda demostrada: a saber, el Derecho natural nace de la íntima relación entre el objeto y la na-

14. Las citas de De Legibus de Francisco Suárez de la sección 2 están tomadas de la versión española por José Ramón Eguillor Muniozguren, S. I.: F. SUÁREZ, Tratado de las leyes y de Dios legislador, vols. 6 (Instituto de Estudios Políticos, Madrid, 1967-1968). Se utilizará la traducción en castellano de esta edición (de ahora en adelante, ed. IEP). Por último, la cita del texto se encuentra en F. SuÁrEZ, De Legibus I, 3, n. 12 (ed. IEP, vol. I, 17).

15. Ibidem, I, 3, n. 13 (ed. IEP, vol. I, 18).

16. Ibidem, I, 3, n. 11 (ed. IEP, vol. I, 17).

17. Ibidem, II, 13, n. 2 (ed. IEP, vol. I, 150).

18. Ibidem, II, 8, n. 5 (ed. IEP, vol. I, 134).

19. Ibidem, II, 7, n. 1 (ed. IEP, vol. I, 129).

20. Ibidem, II, 7, n. 4 (ed. IEP, vol. I, 129).

21. Ibidem, II, 7, n. 5 (ed. IEP, vol. I, 130). 
turaleza $^{22}$, ya sea por un principio o por una consecuencia por muy remota que sea ${ }^{23}$. Pari passu, Francisco Suárez desarrolla las características del Derecho natural que son la unidad y la inmutabilidad. La primera, Suárez indica, es "una sola en todos los hombres y en todas partes ${ }^{24}$, en todos los tiempos y en todas las situaciones de la naturaleza humana ${ }^{25}$ " y la segunda, desarrollada en los capítulos XIII al XVII del libro II del tratado De Legibus, observa que "la ley [Derecho] no puede degenerar ni cambiar por sí misma, ni en general ni en casos particulares" ${ }^{26}$.

El jesuita granadino desarrolla ${ }^{27}$ el concepto de Derecho de gentes mediante su propia argumentación (capítulos XIX y XX) y su rechazo a las falsas sentencias (capítulos XVII y XVIII). Su rechazo a las falsas opiniones son cuatro $^{28}$, con lo que la postura entre el Derecho de gentes y el Derecho natural de Francisco Suárez sólo conoce una diferencia básica, esto es, la no intrínseca necesidad de sus preceptos ${ }^{29}$. La posición del doctor eximio respecto al Derecho de gentes es sencillamente positivo humano ${ }^{30}$, establecido por los hombres, no natural. Para este autor, el Derecho de gentes tiene un objetivo concreto ${ }^{31}$ cuya función no es complementaria simplemente $^{32}$. Como se ha indicado antes, el Derecho de gentes tiene una doble naturaleza: entre el natural y positivo estricto. Éste posee

22. Ibidem, II, 7, nn. 6, 7 y 10 (ed. IEP, vol. I, 130-132).

23. A. Ferreiro López, op. cit., 452.

24. F. SuÁREZ, De Legibus II, 8, n. 5 (ed. IEP, vol. I, 134).

25. Ibidem, II, 8, n. 8 (ed. IEP, vol. I, 135).

26. Ibidem, II, 13, n. 2 (ed. IEP, vol. I, 150).

27. A. Ferreiro López, op. cit., 455.

28. F. SuÁrEZ, De Legibus II, 17, nn. 3-9, con especial referencia a los números 5, 7, 8 y 9 (ed. IEP, vol. I, 180-184); Ibidem, II, 18, nn. 1-9, con especial referencia a los números 2 y 9 (ed. IEP, vol. I, 184-187).

29. "Para que el derecho de gentes se distinga del derecho natural, es necesario que, aun suponiendo tal materia, no se siga por una deducción evidente sino por una deducción menos cierta, de tal manera que el que decida, más que la necesidad sea la libre voluntad humana y la convivencia moral", Ibidem, II, 17, n. 9 (ed. IEP, vol. I, 183).

30. Ibidem, II, 19, n. 3 (ed. IEP, vol. I, 188).

31. "El derecho de gentes no se introdujo como a falta de ley sino como necesario de suyo y porque de suyo exige esa manera de ser, ya que no podrá introducirse de otro modo a la manera humana", Ibidem, VII, 3, n. 7 (ed. IEP, vol. IV, 780).

32. "Este derecho es tenido por ley cuando falta ley", Ibidem. 
propiedades de ambos; de hecho, interviene en las propiedades del Derecho natural ${ }^{33}$ así como también en aquellas propiedades pertenecientes a las de Derecho positivo estricto ${ }^{34}$. Este jesuita ofrece una doble modalidad del Derecho de gentes: una, el Derecho de gentes internacional ${ }^{35} \mathrm{y}$, otra segunda, el Derecho de gentes nacional ${ }^{36}$. La primera modalidad ${ }^{37}$ recoge el espíritu verdadero — despolitizadode la Sociedad de Naciones que aglutina diferentes temas como la práctica de los embajadores, el comercio, el derecho a la guerra, la esclavitud, los tratados de paz y las treguas ${ }^{38}$. Esta modalidad tiene como objetivo $^{39}$ ofrecer paz y conciliación en las relaciones entre los pueblos “inter se", con unos preceptos básicos comunes ${ }^{40}$. La segundad modalidad ${ }^{41}$, en cambio, no tiene el propósito de establecer la

33. Suárez indica que el Derecho de gentes "se deduce como a impulso de la naturaleza”, Ibidem, II, 19, n. 3 (ed. IEP, vol. I, 188).

34. "El derecho de gentes no se funda en solo el instinto natural", Ibidem, II, 19, n. 6 (ed. IEP, vol. I, 189); "El derecho de gentes (...) es un derecho común a todos los pueblos impuesto no por instinto de sola la naturaleza sino por el uso de los pueblos", Ibidem.

35. "Una, que es un derecho que deben observar todos los pueblos y las distintas gentes entre sí", Ibidem, II, 19, n. 8 (ed. IEP, vol. I, 190).

36. "Otra, que es un derecho que cada uno de los estados o reinos observa en su interior, pero que por la semejanza o coincidencia con los otros, se llama derecho de gentes", Ibidem.

37. "La primera modalidad es en la que con más propiedad entra el derecho de gentes realmente distinto del derecho civil", Ibidem.

38. Ibidem.

39. "La razón de esta parte y de este derecho es que el género humano, por muy dividido que esté en distintos pueblos y reinos, siempre tiene alguna unidad, no sólo específica sino también - por decirlo así- política y moral: a ella se refiere el precepto natural del mutuo amor, el cual alcanza a todos, aun a los extraños y de cualquier pueblo", Ibidem, II, 19, n. 9 (ed. IEP, vol. I, 190).

40. "Se confirma lo que decíamos antes del derecho de gentes, pues, aunque el género humano no estuvo reunido en un cuerpo político sino dividido en distintas comunidades, sin embargo, para que esas comunidades pudiesen ayudarse mutuamente y conservarse en la justicia y en la paz — cosa que era necesaria para el bien de la humanidad - convino que, como por un pacto y consentimiento común, observasen entre sí algunos derechos comunes: esto es lo que se llama derechos de gentes, el cual, según hemos dicho, se introdujo más por tradición y costumbre que por constitución alguna", Ibidem, III, 2, n. 5 (ed. IEP, vol. II, 203).

41. "La segunda modalidad del derecho de gentes contiene ciertos preceptos o ritos y maneras de vida que de suyo y directamente no afectan a todos los hombres ni tienen — como quien dice - por fin próximo la conveniente asociación y comunicación de todos los pueblos entre sí, sino que en cada uno de ellos los determina 
paz entre los pueblos sino regular la asociación y la comunicación entre las personas dentro de una misma nación "intra se". Este segundo tipo de derecho de gentes, que engloba otros preceptos, ritos o maneras de vivir ${ }^{42}$, es común a todos y sin embargo no es natural ${ }^{43}$. Las propiedades de ambas modalidades son dos: universalidad ${ }^{44} \mathrm{y}$ mutabilidad $^{45}$, características que Suárez indica en su libro De Legibus en diferentes lugares. En definitiva, Francisco Suárez define el Derecho de gentes como universal, mudable, y positivo y humano, a pesar de diferir del civil, pues sus instituciones son anteriores al Estado en general ${ }^{46}$, y éste no puede suprimirlas o cambiarlas del mismo modo y manera que cambia o suprime cualquier otra institución legal ${ }^{47}$.

\section{El derecho de propiedad en Francisco Suárez}

Francisco Suárez efectúa una triple clasificación respecto al derecho de propiedad: el dominio, la propiedad privada y el dominio-propiedad. La obra suareciana no desarrolla estos tres conceptos con gran precisión; por ejemplo, los términos 'dominio' y 'propiedad' varían según el texto y su localización ${ }^{48}$, aunque se puede esbozar

el régimen que conviene para su gobierno particular; y sin embargo son de tal naturaleza que en el uso de tales ritos y leyes casi todos los pueblos coinciden entre sí y tienen semejanza, unas veces genérica y otras específica”, Ibidem, II, 19, n. 10 (ed. IEP, vol. I, 191).

42. Entre otros, el culto a Dios, la ocupación de emplazamientos, los edificios, el avalladamiento, el uso del dinero, contratos particulares (compra, venta y otros semejantes), el postliminio o la prohibición de los matrimonios con los extraños en religión, Ibidem.

43. Ibidem, II, 20, n. 1 (ed. IEP, vol. I, 191).

44. "Ambos [el Derecho natural y el Derecho de gentes] son de alguna manera comunes a todos los hombres, y por este capítulo - si nos paramos en solo el nombreambos pueden llamarse de gente", Ibidem, II, 19, n. 1 (ed. IEP, vol. I, 187).

45. "El derecho de gentes lo pueden cambiar no sólo Dios sino también los hombres", Ibidem, II, 15, n. 10 (ed. IEP, vol. I, 165).

46. A. PABST, Modern sovereignty in question: theology, democracy and capitalism, "Modern Theology" 26/4 (octubre 2010) 570-602, en especial las páginas 578-580.

47. A. Ferreiro López, op. cit., 460.

48. Las citas de De mysteriis vitae Christi de Francisco Suárez están tomadas de la versión castellana del padre Romualdo Galdós, S. I.: F. SuÁreZ, Misterios de la Vida de Cristo, vol. I (BAC, Madrid, 1948) (Disputas 1-32). De la misma obra, el tema 
unos principios básicos elementales. En primer lugar, el concepto de dominio está ilustrado en su obra De Opere sex Dierum ${ }^{49}$ cuando señala las clases de dominio que el hombre recibió en su creación. La naturaleza de este dominio es una característica perteneciente a Dios sólo, que es universal, completo y perfectísimo ${ }^{50}$. A su vez, Dios concedió, permitió e hizo partícipe de su dominio al hombre $^{51}$, sujeto dotado con una potestad de superioridad frente a todas las criaturas y los seres de la creación (Gn. 1, 26-28) ${ }^{52}$. Para Suárez, el concepto de dominio posee tres elementos: la capacidad ${ }^{53}$, la potestad $^{54}$ y el uso ${ }^{55}$. Y, por su lado, el doctor eximio establece dos clases de dominio: de jurisdicción (de gobierno) y de propiedad. El primero $^{56}$ sólo da potestad de gobernar y dirigir a los súbditos, y se

de la propiedad y del dominio es tratado en F. SuÁREZ, Misterios, disp. 28, sec. 2, 9-13 (ed. BAC, vol. I, 770-775). Asimismo, las menciones de Defensio fidei tienen su origen en la edición traducida por José Ramón Eguillor Muniozguren, S. I.: F. SuÁREZ, Defensa de la fe católica y apostólica contra los errores del anglicanismo, vols. 4 (Instituto de Estudios Políticos, Madrid, 1970-1971). Se utilizará la traducción en castellano de esta edición (en adelante, ed. IEP). Por otro lado, las citas de las obras De opere sex dierum, De virtute et statu religionis, De fide, spe et charitate y Varia opuscula theologica de Francisco Suárez han sido recogidas del artículo A. FERREIRO LóPEZ, op. cit. Para ver el tratamiento de los términos "dominio" y "propiedad", véase las obras de F. SuÁreZ, De Virtute, VIII, 5, nn. 4 y 6 y la obra De Fide, disp. 22, sec. 6, n. 6 (citados en A. FERreIro López, op. cit., 460).

49. "Quae potestas aliquod genus dominii est", F. SUÁREZ, De Opere sex Dierum, III, 16, n. 17 (citado en A. FERREIRO LóPEZ, op. cit., 461).

50. F. SuÁrez, De Opere sex Dierum, III, 16, n. 1. y F. SuÁreZ, Opuscula theologica, sec. II, 21 (citados en A. FERREIRO LóPEZ, op. cit., 461).

51. F. SuÁreZ, De Opere sex Dierum, III, 16, 1 (citado en A. FerreIro LóPEZ, op. cit., 461).

52. Sagrada Biblia, versión directa de las lenguas originales por Eloino Nácar Fuster y Alberto Colunga Cueto, O.P. (BAC, Madrid, 1993) 3-4.

53. F. SuÁreZ, De Opere sex Dierum, III, 16, nn. 5 y 6 (citado en A. Ferreiro LópeZ, op. cit., 461), donde este último autor señala que estas facultades son: el entendimiento y la voluntad, con su consecuencia la libertad. Además, véase F. T. BACIERO RuIZ, Derecho de propiedad cit., 401.

54. F. Suárez, De Opere sex Dierum, III, 16, nn. 8 y 9 (citado en A. Ferreiro López, op. cit., 461). Ferreiro López destaca la relación de superioridad con la existencia del hecho físico y de la potestad moral. Igualmente consúltese F. T. BACIERO RUIZ, Derecho de propiedad cit., 395-396.

55. F. SuÁrez, De Opere sex Dierum, III, 16, n. 5 (citado en A. Ferreiro López, op. cit., 462). Ferreiro López indica que la potestad es el 'actus primus'; el uso, el 'actus secundus'.

56. F. Suárez, De Fide, disp. 22, sec. 6, n. 6 (citado en A. Ferreiro López, op. cit., 462). 
concede en utilidad de éstos; el segundo ${ }^{57}$ da la facultad al dueño (dominus) para usar del objeto de su dominio con todos los usos lícitos y convenientes a su naturaleza y extraer sus utilidades para emplearlos en el propio provecho. En segundo lugar, la propiedad privada es la organización práctica de esta facultad moral, en virtud de la cual los hombres utilizan los bienes apropiándoselos de una manera propia, estable y exclusiva ${ }^{58}$. Las palabras 'propiedad' y 'dominio' no son siempre sinónimas de propiedad privada para Francisco Suárez; por el contrario, atribuye las expresiones 'de divisione dominiorum' u otras parecidas cuando habla del régimen de propiedad privada ${ }^{59}$. Puede que la definición más completa de propiedad privada en Francisco Suárez es la siguiente: "principa$1 \mathrm{e}^{60}$ jus disponendi de re aliqua in quemqumque usum ${ }^{61}$ lege non prohibitum" 62 , si bien pueden encontrarse otras definiciones suarecianas del Derecho de propiedad privada en las obras de De Virtute et Statu Religionis ${ }^{63}$ y en De mysteriis vitae Christi ${ }^{64}$. Por último, el tercer concepto del Derecho de propiedad en Francisco Suárez es el 'dominio-propiedad', definición híbrida que el antiguo y erudito canónigo magistral de la Catedral de Jaén propone ${ }^{65}$ entre el concepto de dominio y propiedad privada. El 'dominio-propiedad' se define como la relación de superioridad concrecionada en la facultad moral de utilizar los bienes creados para su provecho. De tal modo que el dominio es un género y la propiedad una de sus especies, concepto éste último que se ha definido antes. Suárez identifica el dominio-propiedad como la potestad que el hombre tiene

57. Ibidem, disp. 22, sec. 6, n. 7; F. SuÁreZ, De Opere sex Dierum, V, 7, n. 9; F. SuÁreZ, De Legibus I, 8, n. 4 (obras citadas en A. FerReIro LóPEZ, op. cit., 462).

58. A. FerReiro López, op. cit., 464.

59. F. SuÁrez, De Opere sex Dierum, V, 7, n. 17 (citado en A. Ferreiro López, op. cit., 463).

60. F. SuÁrez, De Virtute, VIII, 5, n. 5 (citado en A. Ferreiro LóPEZ, op. cit., 463).

61. Ibidem, VIII, 5, nn. 6-12 (citado en A. FerreIro LópeZ, op. cit., 463).

62. Ibidem, VIII, 5, n. 4 (citado en A. Ferreiro López, op. cit., 463); F. T. Baciero RUIZ, Derecho de propiedad cit., 397.

63. F. SuÁrez, De Virtute, VIII, 5, n. 29 (citado en A. Ferreiro LópeZ, op. cit., 463).

64. F. SuÁrez, Misterios, disp. 28, sec. 2, n. 9 (ed. BAC, vol. I, 770-771), obra citada - y corregida - en A. FERREIRO LÓPEZ, op. cit., 463.

65. A. FERreiro López, op. cit., 464-465. 
sobre todas las cosas inferiores a él para utilizarlas en su propio provecho y conservarse, perfeccionarse, cumplir el fin consiguiente a su creación ${ }^{66}$. O, dicho de otro modo, el hombre tiene por Derecho natural ${ }^{67}$ dominio-propiedad ${ }^{68}$ en todos los bienes de la creación inferiores a él ${ }^{69}$.

Tal y como se ha señalado en el punto anterior b), la naturaleza de la propiedad privada en Francisco Suárez es un punto fundamental a debatir ${ }^{70}$. Por un lado, Francisco Suárez razona que la propiedad privada —o división de los bienes en su terminología — no es de Derecho natural. Expone cuatro argumentos concretos. El primer argumento subraya la idea de que hay muchas situaciones en que el Derecho natural no exige ni prohíbe, pero permite. Como ejemplo, explica que la comunidad de bienes es de Derecho natural "sólo permisivamente, o negativamente, o concesivamente" 71 , por lo que la división y apropiación individual de esos bienes — como régimen opuesto al primero - no puede ser de Derecho natural, al menos preceptivamente, pues el Derecho natural no puede exigir y permitir dos cosas contradictorias al mismo tiempo ${ }^{72}$. No obstante, el Derecho natural no manda que la comunidad de bienes permanezca intacta, sino que su estabilidad y perseverancia "lo deja a la libre disposición de los hombres según la exigencia de la razón"73. En caso de que la comunidad de bienes desaparezca, la división y apropiación de los mismos es el otro modo de organizar el dominio-propiedad, por lo que dicha división no sería de Derecho natural aunque no es

66. F. Suárez, De Opere sex Dierum, III, 16, nn. 1 y 4 (citado en A. Ferreiro López, op. cit., 462).

67. Ibidem, III, 16, nn. 2 y 6 (citado en A. FERREIRO LÓPEZ, op. cit., 465).

68. Ibidem, III, 16, n. 9; F. SuÁREZ, De Charitate, disp. VII, sec. 3, n. 2; sec. 5, n. 7 (obras citadas en A. FERREIRO López, op. cit., 465).

69. F. Suárez, De Opere sex Dierum, III, 16, 2 (citado en A. Ferreiro López, op. cit., 465).

70. Se sigue la clasificación apuntada por A. FERREIRo LóPEZ, op. cit., 18 y ss.

71. F. Suárez, De Legibus II, 14, n. 6 (ed. IEP, vol. I, 156); F. T. Baciero RuIZ, Derecho de propiedad cit., 398; F. T. BACIERO RUIZ, La ley moral natural según Francisco Suárez, "Revista Española de Filosofía Medieval" 14 (2007) 114.

72. F. SuÁreZ, De Legibus II, 14, n. 14 (ed. IEP, vol. I, 158-159); F. T. BACIERO RuIZ, La ley moral natural cit., 114.

73. F. SuÁreZ, De Legibus II, 14, n. 6 (ed. IEP, vol. I, 156). 
incompatible con ésta ${ }^{74}$. El segundo argumento utilizado continúa tratando el asunto de la inmutabilidad del Derecho natural; si éste puede ser cambiado por el poder humano o no ${ }^{75}$. Suárez es categórico y afirma que "el poder humano no puede abrogar ningún precepto del derecho natural ni dispensar de él"76. Para ello, el doctor eximio debe responder a la objeción principal siguiente formulada por Escoto y Gabriel Biel:

[...] antes del pecado los hombres tuvieron el precepto de que todas las cosas fueran comunes pero que después del pecado ese precepto se suprimió, y que así la división de las cosas no fue contraria al derecho natural ${ }^{77}$.

Suárez argumenta que tal precepto no es positivo porque no puede demostrarse, así como tampoco es natural ya que la relación necesaria entre la comunidad de bienes y el estado de inocencia parece nula pues en aquel estado los hombres hubiesen podido tomar para sí y dividir entre sí algunas cosas — sobre todo cosas muebles- para su uso ordinario ${ }^{78}$. Este doctor jesuita califica las observaciones - de Escoto- como conjeturas ya que sólo demuestra que la división de los bienes no fue necesaria o, a lo sumo, que sería más útil la posesión en común de los mismos en aquel estado. Por tanto, la división de los bienes demuestra que es más apropiada al estado actual de naturaleza pero no se puede deducir que sea intrínsecamente necesaria, de Derecho natural ${ }^{79}$. El tercer argumento desarrolla la cuestión de la división y la apropiación de los bienes del género humano en el estado de inocencia en el libro $\mathrm{V}$ de la obra De Ope-

\section{A. Ferreiro López, op. cit., 467.}

75. F. SuÁREZ, De Legibus II, 14, n. 1 (ed. IEP, vol. I, 153-154). El doctor eximio puntualiza que "por derecho natural todas las cosas eran comunes, y sin embargo los hombres introdujeron el reparto de las cosas", Ibidem, II, 14, n. 2 (ed. IEP, vol. I, 154).

76. Ibidem, II, 14, n. 5 (ed. IEP, vol. I, 155).

77. Ibidem, II, 14, n. 13 (ed. IEP, vol. I, 158).

78. Ibidem; N. SAN EMETERIO MarTín, Sobre la propiedad. El concepto de propiedad en la Edad Moderna (Tecnos, Madrid, 2005) 62.

79. A. Ferreiro López, op. cit, 469. Las consecuencias de este argumento son explicadas en F. SuÁrEZ, De Legibus II, 14, nn. 17 y 18 (ed. cit., vol. I, 159-160). 
re Sex Dierum. Francisco Suárez acepta el destino universal de los bienes, tanto en el estado de naturaleza íntegra como en el estado de naturaleza caída ${ }^{80}$ y vuelve a señalar que la división de los bienes no es de Derecho natural. No obstante, este autor jesuita reconoce la posibilidad de que existiese cierta división de los bienes muebles, de consumo o de la tierra cultivada por su utilidad para los seres humanos en el estado de inocencia ${ }^{81}$. Por su parte, Francisco Suárez señala un último argumento acerca del origen del Poder civil ${ }^{82}$ y lo aplica al caso de la propiedad en su obra titulada Defensa de la Fe. En ella se explica el origen del dominio humano con el ejemplo de la propiedad privada sobre las cosas inferiores ${ }^{83}$, donde expone que Dios dio el dominio de los bienes a toda la comunidad, pero sin mandar que así permanecieran perpetuamente o que se cambiaran, sino que lo dejó al arbitrio de los hombres ${ }^{84}$.

\section{El derecho de propiedad privada o división de los bienes en Francisco Suárez es de Derecho de gentes}

En efecto, Francisco Suárez apunta que la naturaleza del Derecho de propiedad privada —o división de los bienes - es de Derecho de gentes y no puede contradecir el Derecho natural, por lo que la división de los bienes tiene el objetivo de servir las necesidades de

80. F. SuÁreZ, De Opere sex Dierum, V, 7, 17 (citado en F. T. Baciero Ruiz, Derecho de propiedad cit., 405).

81. Ibidem, V, 7, nn. 17-18 (citado en A. Ferreiro LópeZ, op. cit., 470-473).

82. "Ese poder, tal como Dios lo da inmediatamente a la comunidad, (...) puede llamarse de derecho natural negativamente, no positivamente, o, más bien, de derecho natural concesivo, no sencillamente preceptivo. Porque indudablemente el derecho natural da de suyo e inmediatamente ese poder a la comunidad, pero no prescribe terminantemente que dicho poder permanezca siempre en ella ni que sea ejercido inmediatamente por ella, sino únicamente mientras la misma comunidad no determine otra cosa, o también mientras otro que tenga poder para hacerlo no introduzca mudanza legítimamente", F. SuÁrez, Defensio Fidei, III, 2, n. 9 (ed. IEP, vol. II, 220).

83. Ibidem, III, 2, n. 14 (ed. IEP, vol. II, 222).

84. A. Ferreiro López, op. cit., 473. Francisco Suárez desarrolla este argumento: "Aunque el poder legislativo en absoluto sea de derecho natural, su concreción en una determinada forma de poder y gobierno depende de la libre voluntad humana”, F. SuÁrEZ, De Legibus III, 4, n. 1 (ed. IEP, vol. II, 206). 
todos los hombres ${ }^{85}$. Por esta razón, en un primer ejemplo, Suárez discute el precepto de la limosna y la limitación de la propiedad privada en su obra De Charitate para determinar que las leyes dirigidas a proteger la "propiedad privada superflua" no son de obligado cumplimiento (si hay gente necesitada en la sociedad) ${ }^{86}$. Suárez declara que "los pobres o los necesitados tienen libre uso de la 'propiedad privada superflua' de los ricos" ${ }^{87}$. De la misma manera, la obra De Legibus de Francisco Suárez confirma que la naturaleza jurídica del Derecho de propiedad privada es de Derecho de gentes en varios lugares ${ }^{88}$. Por último, otras dos obras del doctor eximio incorporaron la idea de que la división de los bienes fue incorporada por el Derecho de gentes también. La primera obra titulada De virtute et statu religionis ofrece dos argumentos ${ }^{89}$ : por un lado, Suárez no rechaza el voto de pobreza y la posesión en común de los religiosos; y,

85. F. SuÁREZ, De Charitate, disp. VII, sec. 3, n. 2 (citado en A. FerreIro López, op. cit., 474-475).

86. A. Ferreiro López, op. cit., 475.

87. R. Wilenius, The social and political theory of Francisco Suárez, "Acta Philosophica Fennica" XV (1963) 90-91.

88. "[...] asignarles un derecho natural distinto: en el estado de integridad el derecho natural exigía v. g. la libertad de todos los hombres, la comunidad de bienes, y cosas semejantes; en cambio en el estado de corrupción exige la esclavitud, el reparto de los bienes, etc., [...]. Pero esa distinción no es necesaria. En primer lugar, porque los ejemplos que se aducen y otros semejantes no pertenecen al derecho natural propiamente dicho y positivo, sino al derecho de gentes". F. SUÁREZ, De Legibus II, 8, nn. 8 y 9 (ed. IEP, vol. I, 135).

Francisco Suárez declara que "[...] Muchas veces puede suceder que, aunque la ley humana o el derecho de gentes o la voluntad privada introduzca algún cambio en las cosas, después la obligación de obrar de esta o de la otra manera nazca inmediatamente de la natural. Eso es lo que sucede en los casos que se han propuesto [...] de la división de la propiedad [...]”. Ibidem, II, 9, n. 12 (ed. IEP, vol. I, 138).

"La respuesta que se puede dar es que, aunque estos preceptos no sean completamente necesarios por la ley natural, sin embargo son tan conformes a la naturaleza que todos los gentiles los introdujeron y aceptaron, y que esto basta para que - prescindiendo de una prohibición positiva de Dios- los hombres pecaran al quebrantarlos. A esto se replica que de ahí se sigue que esos preceptos a lo más pertenecen al derecho de gentes: este parece ser el pensamiento de Escoto cuando los compara con la división de la propiedad. Pero el derecho de gentes lo pueden cambiar no sólo Dios sino también los hombres, porque, si alguna región no hubiese adoptado la división sino conservarse la comunidad de bienes, no podríamos condenarlo como malo", Ibidem, II, 15, n. 10 (ed. IEP, vol. I, 165).

89. F. Suárez, De Virtute, VIII, 8, n. 22 (citado en A. FERreiro López, op. cit., 476). 
por otro lado, reitera la idea de que la propiedad privada fue introducida por este Derecho de gentes, pero no de un modo imperativo para todos los hombres en particular sino con carácter general. La segunda obra denominada Defensio fidei catholicae adversus anglicanae sectae errores trata el origen de la propiedad privada dentro de la teoría política suareciana, por lo que ofrece dos reflexiones: primero ${ }^{90}$, insiste que Dios hizo comunes todos los bienes y la apropiación y la división de los bienes vienen del Derecho de gentes, ayudado por el derecho civil; segundo ${ }^{91}$, recuerda que ningún propietario recibió su autoridad $^{92}$ —o Derecho de propiedad — de Dios de forma directa.

\section{LA CUESTIÓN FISCAL EN FranCISCO SUÁREZ}

Las ideas tributarias de la Escuela de Salamanca ${ }^{93}$ han sido analizadas por diversos autores. El doctor eximio no fue una excepción, puesto que analizó la cuestión fiscal ${ }^{94}$ en el tomo $\mathrm{V}$ de la obra Tractatus de Legibus ac Deo Legislatore ${ }^{95}$. Francisco Suárez definió el concepto de

90. F. Suárez, Defensio Fidei, III, 2, 14 (citado en A. Ferreiro López, op. cit., 476).

91. Ibidem, III, 2, n. 10 (citado en A. FERREIRo LóPEZ, op. cit., 476-477).

92. A. J. CarlyLe, La libertad política (Fondo de Cultura Económica, Madrid, 1982) 109.

93. G. Higuera, Impuestos y moral en los siglos XVI y XVII, "Miscelánea Comillas: Revista de Ciencias Humanas y Sociales" 21/40 (1963) 5-50; J. GorosQuiETA REYES, El sistema de ideas tributarias de los teólogos y moralistas principales de la Escuela de Salamanca (Siglos XVI y XVII), "Hacienda Pública Española" 17 (1972) 131-150; M. GRiCE-HuTCHINSON, El pensamiento económico en España (1177-1740) (Crítica, Barcelona, 1982); M. GRICE-HUTCHINSON, Ensayos sobre el pensamiento económico en España (Alianza, Madrid, 1995); F. GÓMEZ CAMACHO, Economía y filosofía moral cit., cap. 7, 293-307; E. FUENTES QUINTANA (coord.), Economía y economistas españoles, Tomo 2. De los orígenes al mercantilismo (FUNCAS-Galaxia GutenbergCírculo de Lectores, Barcelona, 1999) 101-358; L. Perdices DE Blas, J. REVUELTA LÓPEZ, Mercado y fiscalidad: Los principios tributarios modernos y la Escuela de Salamanca, "Esic Market" 138 (2011) 117-143; y, por último, P. GómEZ-CaLERO VALDÉs, Francisco Suárez, R. SÁNCHEZ LissEn (coord.), Economía y economistas andaluces (siglo XVI a XX) (Ecobook- Editorial del Economista, Madrid, 2013) 97111.

94. C. Digon, J. E. Leonetti, Presencia de los principios fundamentales de la tributación, en J. Cruz Cruz (ed.), La gravitación moral de la ley según Francisco Suárez (Eunsa, Pamplona, 2009) 137-144.

95. Para estudiar la cuestión fiscal y tributaria del subtítulo 3, hemos utilizado las citas de De Legibus de Francisco Suárez de la edición crítica bilingüe por C. Baciero, A. 
impuesto ${ }^{96}$ y apuntó que "las leyes tributarias son onerosas y se clasifican entre las odiosas" 97 . A su vez, indicó que "las leyes por las que se manda pagar dichos tributos, aunque en ellas se añada una pena, no hay duda alguna de que no pueden llamarse puramente penales sino morales" "98 y subrayó que "esas leyes obligan en conciencia a pagar tales tributos íntegra y espontáneamente sin disminución alguna y $\sin$ fraude, aunque no se reclamen" 99 . No obstante, Suárez duda sobre otros tributos y plantea razones fundadas para observar si el pago del impuesto "guarda la equidad de la justicia que se requiere para tal obligación"100, por lo que concluye que "las leyes tributarias serán moderadas y soportables, mientras que entendidas con un rigor mayor serán demasiado duras y quizás injustas" ${ }^{101}$. Francisco Suárez completa el capítulo XIII indicando que las leyes tributarias pueden dictarse de tres maneras ${ }^{102}$, a saber, "mediante simple mandato sin añadir pena, mandando y añadiendo al mismo tiempo pena para los que no paguen, e imponiendo tributo con la única carga de la pena sin interposición de mandato" ${ }^{103}$. Parece evidente que el

M. Barrero, J. M. García Añoveros y J. M. Soto: F. SuÁREZ, Tractatus de Legibus ac Deo Legislatore. Libro V: Sobre la variedad de las leyes humanas y especialmente sobre las odiosas, Corpus Hispanorum de Pace, segunda serie, vol. 16 (Consejo Superior de Investigaciones Científicas, Madrid, 2010) 267-373. Se utilizará la traducción en castellano de esta edición (en adelante, ed. CSIC).

96. "Significa el impuesto público que se distribuye a través de cada uno de los ciudadanos para los gastos regios y las obras públicas de la comunidad política y se entrega según se establece por ley", F. SuÁREZ, De Legibus V, 13, n. 1 (ed. CSIC, vol. 16, 267).

97. Ibidem.

98. Ibidem, V, 13, n. 4 (ed. CSIC, vol. 16, 271).

99. Ibidem (ed. CSIC, vol. 16, 273). Suárez continúa su explicación: "La razón es que son deudas debidas por justicia conmutativa, la cual lleva consigo esa obligación intrínseca, salvo que conste por la costumbre o por documento escrito que fue otra la condición del pacto o de la carga que se impuso a las cosas mismas, pues en ese caso se han de observar la costumbre y la escritura dichas", Ibidem.

100. Ibidem, V, 13, n. 5 (ed. CSIC, vol. 16, 273).

101. Ibidem.

102. La promulgación de las leyes tributarias de Francisco Suárez son desarrolladas por tres maneras o tesis distintas, véase Ibidem, V, 13, nn. 6-13 (ed. CSIC, vol. 16, 275-283).

103. Ibidem, V, 13, n. 6 (ed. CSIC, vol. 16, 275). Suárez añade que la ley tributaria se pueden y deben distinguir dos partes: "Una es la que manda o impone el tributo, la otra es la que impone la pena a los que no pagan el tributo", Ibidem. 
granadino dedicó grandes esfuerzos a reflexionar sobre la justicia de las leyes tributarias y las condiciones mínimas que un impuesto debe cumplir para ser considerado justo y equitativo. Suárez clasificó tres condiciones esenciales para que cualquier tributo pueda ser estimado justo: 1) potestad legítima de la autoridad; 2) razón y causa final del tributo; y, 3) forma o proporción y materia del tributo.

\section{Las tres condiciones de la justicia tributaria según Francisco Suárez}

La primera condición ${ }^{104}$ de un impuesto justo requiere "potestad para imponer el tributo en aquél que establece dicha ley, de lo contrario no será justa sino tiránica"105. Para Francisco Suárez, no toda potestad basta para imponer tributo; por el contrario, "el tributo sólo lo puede imponer un príncipe que no reconoce superior en su ámbito" ${ }^{106}$. El doctor eximio señala quiénes tienen esta potestad en la comunidad política ${ }^{107} \mathrm{y}$, en concreto, subraya que el papa no puede, a no ser por un fin espiritual, imponer en lo temporal tributos a territorios que no son suyos; como tampoco lo puede hacer ningún concilio ${ }^{108}$. De especial interés resulta la afirmación que no sólo son justos los tributos de los que consta que han sido impuestos por reyes y príncipes supremos, sino también aquellos de los que no consta quién los ha impuesto, con tal de que se hayan introducido por una costumbre de cuyo comienzo no existe memoria ${ }^{109}$. Del mismo modo, Francisco Suárez plantea la duda sobre la potestad

104. Ibidem, V, 14, nn. 1-17 (ed. CSIC, vol. 16, 285-305).

105. Ibidem, V, 14, n. 1 (ed. CSIC, vol. 16, 285). En este mismo sentido, Suárez agrega que "la imposición de tributos es un asunto muy serio y precisa mucha reflexión para que se realice con justicia", Ibidem, V, 14, n. 14 (ed. CSIC, vol. 16, 303).

106. Ibidem, V, 14, n. 1 (ed. CSIC, vol. 16, 285). No obstante, Suárez reconoce que "puede sin duda el príncipe encargar a un inferior que, en su nombre y autoridad, imponga un tributo en un caso particular y después de examinar la causa, la razón y la manera, (...); pero no puede en justicia conceder a un inferior el privilegio general de imponer un tributo al margen de su autorización, privilegio que redunda además en beneficio exclusivo del propio inferior", Ibidem, V, 14, n. 17 (ed. CSIC, vol. 16, 305).

107. Ibidem, V, 14, n. 2 (ed. CSIC, vol. 16, 285 y 287).

108. Ibidem, V, 14, n. 3 (ed. CSIC, vol. 16, 287 y 289).

109. Ibidem, V, 14, n. 4 (ed. CSIC, vol. 16, 289). 
para imponer un nuevo tributo por costumbre inmemorial, incluso si aquel que lo impone no es potestad suprema en asuntos temporales ${ }^{110}$. El jesuita destaca que las consecuencias de ello son muy claras y distintas. Una cosa es tener costumbre inmemorial de exigir un tributo que se supone ya impuesto por la misma costumbre, otra cosa es tener costumbre inmemorial de imponer nuevos tributos y consecuentemente exigirlos después ${ }^{111}$. A raíz del planteamiento de esta duda, el teólogo granadino recoge y analiza el debate de los ilustrados Juan de Medina y Alfonso de Castro: el primero ${ }^{112}$, con una postura más intervencionista, afirma que hay que aplicar el mismo criterio con respecto a la potestad para imponer un nuevo tributo por costumbre inmemorial, aunque quien lo imponga no sea el señor supremo; el segundo ${ }^{113}$, con un postura más liberal, afirma que una costumbre antigua, de cuyo comienzo no se tiene memoria, es válida para exigir los tributos que se introdujeron desde aquel tiempo antiguo, pero no para imponer nuevos.

La segunda condición necesaria para la justicia del tributo es su causa final o razón de ser ${ }^{114}$, en el que además se pone de relieve la necesidad de que dicha causa final o razón de ser sea conoci$\mathrm{da}^{115}$. De acuerdo con Francisco Suárez, todos los doctores afirman que para que la causa sea justa es preciso que el tributo se imponga por razones de bien común ${ }^{116}$, no por razones privadas del propio príncipe ${ }^{117}$. Además agrega que los tributos poseen una doble causa inmediata ${ }^{118}$. Una atañe a la persona del príncipe en cuanto tal, la otra se refiere a los gastos comunes (la guerra, la reparación de puentes y caminos, la vigilancia, la compensación de algún perjuicio causado o como castigo de algún delito y, en general, cualquier otra que redunde en beneficio de toda la comunidad y el bien común).

110. Ibidem, V, 14, n. 5 (ed. CSIC, vol. 16, 289).

111. Ibidem.

112. Ibidem, V, 14, nn. 6-7 (ed. CSIC, vol. 16, 291 y 293).

113. Ibidem, V, 14, nn. 8-11 (ed. CSIC, vol. 16, 293-299).

114. Ibidem, V, 15, n. 1 (ed. CSIC, vol. 16, 307).

115. Ibidem.

116. N. San EMETERIO Martín, op. cit., 80-81.

117. F. SuÁrEZ, De Legibus V, 15, n. 2 (ed. CSIC, vol. 16, 307).

118. Ibidem, V, 15, n. 3 (ed. CSIC, vol. 16, 309). 
Suárez observa que

[...] al igual que es necesaria la justicia de la causa, así también es necesaria la proporción entre el tributo y su causa para mantener el equilibrio de la justicia conmutativa, que se da entre cosa y cosa, pues un tributo puede imponerse en justicia hasta donde es necesario y suficiente para su fin ${ }^{119}$.

No obstante, incluye otra condición que es el uso, a saber, que el tributo se destine a aquel uso para el cual se ha impuesto ${ }^{120}$. Asimismo, el doctor eximio comenta los requisitos de justicia en los tributos reales y comunes ${ }^{121}$. Explica que la justicia de los tributos reales no depende de su uso; el rey es verdaderamente su dueño y puede disponer libremente de ellos sin cometer injusticia, con tal de que se ocupe de las obligaciones políticas que le son propias. Por el contrario, la justicia de los tributos para las obras comunes es clara: el tributo debe ser empleado en la obra para la cual se impuso; de no ser así, se comete fraude e injusticia ${ }^{122}$. De ello, Suárez concreta que el tributo depende de la causa en su origen y en su mantenimiento; si la causa es necesaria para la justicia del tributo, no puede durar más el tributo que la causa, porque, cesando la causa, cesa el efecto. No se observará ni equidad ni justicia si se exige el tributo cesando la causa, porque se está exigiendo ya más de lo necesario ${ }^{123}$. El jesuita agrega una limitación importante: aunque haya cesado una determinada causa en pro de la cual se impuso el tributo, si otra equivalente ocupa su lugar, podrá no cesar el tributo, pues entonces no cesa una causa sin más, sino tal causa, cuya necesidad no es absoluta; y el príncipe tiene en su poder hacer ese cambio; al igual que podría imponer un nuevo tributo, si surgiera una nueva causa ${ }^{124}$. Con el objetivo de guardar la justa proporción,

119. Ibidem, V, 15, n. 4 (ed. CSIC, vol. 16, 309).

120. Ibidem.

121. Ibidem, V, 15, n. 5 (ed. CSIC, vol. 16, 311).

122. Ibidem.

123. Ibidem, V, 15, n. 6 (ed. CSIC, vol. 16, 311).

124. Ibidem, V, 15, n. 7 (ed. CSIC, vol. 16, 313). 
el príncipe estará obligado, no a fijar una nueva imposición aunque sea temporal por cualquier necesidad que se presente, sino a sopesar prudentemente si los tributos antiguos son suficientes en aquellas obras en las que ha cesado o ha quedado en suspenso la necesidad actual de hacer expensas ${ }^{125}$. Por último, el teólogo granadino sugiere si se puede exigir en justicia un tributo cuya causa ha cesado, al menos por razón de una antigua costumbre que haga las veces de la causa $^{126}$. Aquí introduce las posturas de Antonio de Córdoba ${ }^{127}$, que da una negativa rotunda, y de Juan de Medina ${ }^{128}$, que sostiene una opinión afirmativa. El criterio de Francisco Suárez es desarrollado posteriormente ${ }^{129}$.

La tercera condición necesaria para que el tributo sea justo es la forma o la proporción ${ }^{130}$; ambas expresiones no son otra cosa que la proporción que se ha de guardar entre el tributo y los súbditos a los que se impone. Según Francisco Suárez, la razón es que, además de la proporción entre la cantidad del tributo total y su causa, que se inscribe en la igualdad de la cosa a la cosa, o sea, en la igualdad propia de la justicia conmutativa, hay que guardar la proporción entre el tributo y las personas a las que se imponen ${ }^{131}$. El jesuita subraya que esta proporción se llama forma del tributo y se inscribe en la justicia distributiva ${ }^{132}$ con relación a la comunidad, pero recae sobre la conmutativa con relación a los individuos. Explica que lo justo no es que todos paguen por igual, sino que cada cual pague en función de sus recursos y de su situación. En efecto, al rico se le ha de exigir más que al pobre, en igualdad de circunstancias ${ }^{133}$. Aparte de guardar proporción entre la cantidad del tributo total y su causa así como entre el tributo y las personas a las que se impone, es necesaria una proporción entre las cosas sobre las que se impone un tributo, según

\section{Ibidem.}

126. Ibidem, V, 15, n. 8 (ed. CSIC, vol. 16, 313).

127. Ibidem.

128. Ibidem, V, 15, nn. 8-9 (ed. CSIC, vol. 16, 313 y 315).

129. Ibidem, V, 15, n. 10 (ed. CSIC, vol. 16, 315 y 317).

130. Ibidem, V, 16, n. 1 (ed. CSIC, vol. 16, 319).

131. Ibidem.

132. Ibidem.

133. Ibidem. 
su naturaleza de bien inmueble o de bien mueble de compraventa o artesanía. Esta última proporción es denominada materia del tributo ${ }^{134}$. Por esta razón, Suárez señala que muchos autores escolásticos (Tomás de Vio, Enrique de Segusio, Bartolomé de San Concordio, Juan de Friburgo, Juan Dridoens, Francisco de Toledo, Domingo de Soto y Martín de Ledesma, entre los citados ${ }^{135}$ ) argumentaban que son injustas las gabelas que se impone a los productos adquiridos para uso propio, y que sólo se deben imponer a los productos que se transportan para negociar. Por el contrario, y en la misma línea que Antonino de Florencia, Gabriel Biel, Silvestre Prierio, Ángel de Clavasio, Bartolomé Fumo, Juan de Tabia, Juan de Medina, Martín de Azpilcueta y Luis de Molina, el erudito jesuita sostiene que los impuestos sobre productos que se transportan, se venden o compran para uso privado son justos porque cumplen las condiciones necesarias para que el tributo sea justo, a saber, que se impone por quien tiene autoridad para ello, y por causas justas y proporcionadas ${ }^{136}$. De acuerdo con Suárez, se acredita que el tributo no resulta injusto ni inicuo por ese capítulo, porque, o es injusto por estar prohibido, o porque de por sí y por su naturaleza es intrínsecamente malo ${ }^{137}$. Se prueba que por la sola prohibición humana no se puede decir que el tributo sea malo sin más, esto es, en todas las partes y en todos los reinos o provincias del mundo cristiano, ya que no se halla prohibido en el derecho canónico ${ }^{138}$, y el derecho civil ${ }^{139}$ no basta para eso. Francisco Suárez critica la postura de Tomás de Vio - y de otros autores por extensión - indicando que tales tributos (gabelas o portazgos) no son de por sí injustos ${ }^{140}$ sino que tiene su aplicación en los tributos que se imponen por la sola compra y venta ${ }^{141}$ sobre los bienes necesarios para la alimentación o el vestido, pues los ricos compran también más de estas cosas, si se considera la materia en sí en el fondo y de modo

\section{Ibidem.}

135. Ibidem, V, 16, n. 2 (ed. CSIC, vol. 16, 319 y 321).

136. Ibidem, V, 16, n. 3 (ed, CSIC, vol. 16, 321 y 323).

137. Ibidem, V, 16, n. 4 (ed, CSIC, vol. 16, 323).

138. Ibidem (ed. CSIC, vol. 16, 323 y 325 ).

139. Ibidem, V, 16, n. 5 (ed. CSIC, vol. 16, 325).

140. Ibidem, V, 16, n. 6 (ed. CSIC, vol. 16, 325 y 327).

141. Ibidem, V, 16, n. 7 (ed. CSIC, vol. 16, 327 y 329). 
general. Por consiguiente, reconoce que la condición del tributo, de que la cantidad de la carga se ha de distribuir proporcionalmente según las posibilidades económicas de cada uno, se ha de entender moralmente ${ }^{142}$, siempre que esa diligencia se observe con suavidad, sin perjuicio de los pueblos y sin ocasionar seria dificultad a los príncipes. El teólogo granadino remata su argumento por la influencia negativa de los impuestos, de modo especial en los mendigos y menesterosos: "estos tributos tienen una mala opinión y son enojosos al conjunto de los pobres, harán muy bien los príncipes si prescinden de ellos en lo posible", aunque

[...] mucho más congruente sería imponer cargar similares, y aún más gravosas, a usos que no son necesarios sino que se dedican a refinamientos o a un excesivo boato o a pura curiosidad, con tal de que esos tributos sirvan para aliviar la indigencia o la justa necesidad del reino o del príncipe ${ }^{143}$.

\section{El rechazo del antiguo derecho de Hispania sobre la imposición de tributos de Francisco Suárez}

El autor jesuita cuestiona si se requiere alguna otra condición, ante todo el consentimiento de los súbditos, para que el tributo sea justo ${ }^{144}$. $\mathrm{Su}$ respuesta parece ser negativa, porque no es ninguna de las tres condiciones suficientes (potestad legítima, causa justa y proporción debida) recogidas por Alfonso de Castro y Juan de Medina ${ }^{145}$. Esta condición establece que el rey no puede imponer un nuevo tributo sino después de convocar al reino mediante los procuradores y con la aprobación y aceptación del tributo por parte de ellos ${ }^{146}$. Francisco Suárez no encuentra esta opinión en el derecho común, canónico o civil, ni en los autores antiguos, así como tampoco cree que esta condición sea necesaria en virtud del derecho natural o de gentes, ni

142. Ibidem, V, 16, n. 8 (ed. CSIC, vol. 16, 329).

143. Ibidem, V, 16, n. 9 (ed, CSIC, vol. 16, 331).

144. Ibidem, V, 17, nn. 1-7 (ed. CSIC, vol. 16, 333-339).

145. Ibidem, V, 17, n. 1 (ed. CSIC, vol. 16, 333).

146. Ibidem, V, 17, n. 2 (ed. CSIC, vol. 16, 333). 
tampoco por el derecho común; es más, ni por el derecho antiguo de Hispania ${ }^{147}$. En consecuencia, el doctor eximio discute las dos maneras del establecimiento de la monarquía: o bien de suerte que el príncipe dependa del consentimiento del pueblo o del senado en la promulgación de las leyes, como de quienes tienen el voto definitivo, o bien de suerte que la potestad esté sin más, exclusivamente, en el príncipe, aunque esté obligado a consultar a los suyos ${ }^{148}$. El jesuita granadino aprecia que la segunda manera es más congruente con el régimen monárquico, más usual, y bastante conforme con la prudencia y la justicia, con un régimen adecuado y con la obediencia de los súbditos. Indica que una monarquía plena y perfecta no es contraria al derecho natural; por el contrario, la forma de gobierno monárquica no puede fundarse en el derecho de gentes, ni en el derecho positivo común ni en el derecho civil, sino que atañe al derecho propio de cada una de las comunidades, reinos o provincias; $y$ en un principio se introdujo por pacto voluntario, por guerra justa o por costumbre ${ }^{149}$. En conclusión, el concurso del reino o el consentimiento del pueblo por sí mismo o mediante sus procuradores no es una condición necesaria para que el tributo sea justo y válido ${ }^{150}$. Así, Suárez expone que la justicia del tributo es, por exigencia natural, anterior a dicho consentimiento del pueblo, de modo que el príncipe supremo impone con su propia autoridad mediante promulgación legal un tributo justo y puede en consecuencia obligar al pueblo al consentimiento y a la aceptación del tributo ${ }^{151}$. Ultima el argumento ${ }^{152}$ considerando que aquella ley y costumbre de Hispania de exigir el consentimiento del reino en la imposición de tributos fue una institución peculiar de los reyes concedida por su benignidad, no por una obligación de justicia, desde hace doscientos años o más ${ }^{153}$.

147. Ibidem, V, 17, n. 3 (ed. CSIC, vol. 16, 335).

148. Ibidem, V, 17, n. 4 (ed. CSIC, vol. 16, 335).

149. Ibidem, V, 17, nn. 4-5 (ed. CSIC, vol. 16, 335 y 337 ).

150. Ibidem, V, 17, n. 6 (ed. CSIC, vol. 16, 339).

151. Ibidem.

152. Ibidem, V, 17, n. 7 (ed. CSIC, vol. 16, 339).

153. F. Martínez Marina, Teoría de las Cortes, t. II (Junta General del Principado de Asturias, Oviedo, 2002) 295-376; F. KERN, Derechos del rey y derechos del pueblo (Rialp, Madrid, 1955) 124-139. 
En torno a la obligación y reclamación del pago de impuestos

El capítulo XVIII discute el tema de si las leyes tributarias obligan en conciencia al pago, aunque éste no se pida ${ }^{154}$. Suárez declara que nadie puede dudar de que el príncipe tenga potestad para ordenar el pago del tributo sin esperar reclamación o advertencia alguna y, al mismo tiempo, sostiene que ordenar el pago de lo que se debe sin esperar reclamación no es carga injusta; más aún, ni tampoco demasiado onerosa ${ }^{155}$. No obstante, el instruido jesuita efectúa una clasificación de los diferentes pareceres por parte de algunos autores escolásticos contemporáneos y apunta una primera opinión fundada ${ }^{156}$ en la que se afirma que esas leyes solamente obligan a pagar estos tributos, si el cobrador o el alcabalero se presenta y los reclama, o, a lo sumo, a no engañarlo si interroga, sobre todo bajo juramento, por lo que "de esta manera, esas leyes [tributarias] se hacen tolerables y humanas; de otro modo, serían demasiado onerosas y difíciles de cumplir"157. La segunda opinión existente fija distinciones entre las leyes que obligan al pago de nuevos peajes o gabelas ${ }^{158}$. Siguiendo a Suárez de nuevo, éste explica que nadie está obligado a pagar nuevos peajes, a no ser quien tenga la certeza de que son justos; y que es suficiente excusa el que no conste de su justicia mientras no exista reclamación o cuando su exacción no puede evitarse sin violencia ni fraude ${ }^{159}$. La tercera opinión afirma sin distinción que estas leyes tributarias justas obligan al pago del tributo, aun cuando no se reclame ${ }^{160}$. Suárez prueba esta opinión porque el tributo justo es debido por justicia $-\mathrm{y}$ obediencia- $\mathrm{y}$ todo el mundo está obligado a pagar las deudas de justicia, aunque no se reclamen ${ }^{161}$. Con ello, el doctor eximio observa dificultades para emitir un juicio definitivo, y distingue varios grados de

154. F. SuÁreZ, De Legibus V, 18, n. 1 (ed. CSIC, vol. 16, 341).

155. Ibidem.

156. Ibidem, V, 18, n. 2 (ed. CSIC, vol. 16, 341 y 343).

157. Ibidem, V, 18, n. 3 (ed. CSIC, vol. 16, 343).

158. Ibidem, V, 18, n. 4 (ed. CSIC, vol. 16, 343).

159. Ibidem, V, 18, n. 5 (ed. CSIC, vol. 16, 345).

160. Ibidem, V, 18, n. 6 (ed. CSIC, vol. 16, 347).

161. Ibidem, V, 18, n. 7 (ed. CSIC, vol. 16, 347 y 349). 
justicia en estas leyes ${ }^{162}$ : el primero, el de las leyes cuya justicia consta con certeza desde todos los puntos, moralmente hablando; el segundo, en el extremo contrario, es el de las leyes de cuya injusticia consta con certeza o con gran probabilidad; y, en el tercer grado, el intermedio, a saber, cuando no consta de la injusticia ni de la justicia del tributo. Y razona que las leyes que imponen sin más tributos justos obligan a pagar el tributo no pedido, cuando consta moralmente que la ley es justa ${ }^{163}$. En cambio, y a pesar de los límites, dudas, distinciones y atenuaciones citadas ${ }^{164}$, Francisco Suárez manifiesta que las leyes tributarias injustas, si consta de su injusticia, nunca obligan al pago; no sólo con anterioridad a su reclamación, sino aun en el caso en que se exijan ${ }^{165}$. Su tesis es precisa y considera "que pecan gravemente y están obligados a restituir, no sólo los príncipes que promulgan tales leyes y perciben tales tributos, sino también los oficiales que los cobran, si les consta que las leyes son injustas"166. Además, continúa insistiendo que "aquellas personas a las que se exigen tales tributos pueden lícitamente no pagar el tributo, bien sea ocultándose o bien incluso poniendo algún tipo de resistencia en la medida de lo posible sin grave pugna y escándalo, porque el derecho de defensa es natural. Pueden también emplear anfibologías para no revelar la verdad, pues los interrogatorios que les hacen son injustos y no están obligados a responder de acuerdo con la intención del interrogante"167. Incluso más, llega a decir que

[...] los obligados a pagar tales tributos pueden reparar el daño por otro camino; o no pagando otros tributos justos, si se presenta la ocasión, o de otra manera semejante a ocultas, sin

162. Ibidem, V, 18, n. 10 (ed. CSIC, vol. 16, 351).

163. Ibidem, V, 18, n. 11 (ed. CSIC, vol. 16, 351).

164. Ibidem, V, 18, nn. 13-24 (ed. CSIC, vol. 16, 355-371) de manera principal.

165. Ibidem, V, 18, n. 12 (ed. CSIC, vol. 16, 353).

166. Ibidem.

167. Ibidem. 
violencia ni robo, compensándose a costa de los bienes del príncipe o de quien ha exigido injustamente el tributo ${ }^{168}$.

El docto jesuita es consciente de la aplicación práctica de tan importante materia, con lo que comenta que "es necesario en particular ponderar las cualidades de la persona; es decir, si es rico o pobre, o si está obligado a pagar tal o cual tributo o muchos por diversos capítulos o títulos"169. Además, indica que

[...] es preciso comparar la capacidad y condición de la persona con la carga del tributo o de los tributos, y examinar si respecto de tal persona la carga es gravosa en exceso porque sobrepasa su capacidad y las ganancias o rentas que necesita para el sostenimiento de su persona o de la familia o de una posición conveniente y moderada, teniendo en cuenta su condición y categoría ${ }^{170}$.

Todo ello servirá para formar un juicio en lo que respecta a la excusación u obligación de pagar los tributos en todo o en parte, bajo la condición de si se reclaman o sin ella. Suárez interpreta un mínimo exento ya que "ante todo nunca debe excusarse alguien de pagar todos los tributos, a no ser que sea tan pobre que su indigencia lo excuse" 171 y repite la idea de que

[...] la contribución debe ser proporcionada a las personas y una misma cantidad absoluta no es justa respecto de todos, por eso, si en particular consta que es demasiado gravosa y desproporcionada respecto de tal persona en concreto, quedará excusada de un tanto por ciento, aunque no de la totalidad ${ }^{172}$.

El autor, protagonista de la monarquía absolutista como forma de

168. Ibidem, V, 18, n. 12 (ed. CSIC, vol. 16, 355).

169. Ibidem, V, 18, n. 25 (ed. CSIC, vol. 16, 371).

170. Ibidem.

171. Ibidem.

172. Ibidem, V, 18, n. 26 (ed. CSIC, vol. 16, 371). 
gobierno de su tiempo, concluye con un consejo, esto es,

[...] que este juicio práctico no lo haga cada uno para sí mismo, [...], porque los súbditos no suelen estar suficientemente instruidos para formarse juicio. Cada cual, por lo tanto, debe seguir el consejo de una persona docta y prudente o del confesor, los cuales por lo general y en igualdad de circunstancias deben inclinar al súbdito hacia el pago del tributo, sobre todo antes de proceder, porque el derecho del rey es de suyo mayor y más cierto ${ }^{173}$.

\section{CONCLUSIÓN}

Las aportaciones de este destacado jesuita son muy notorias en el campo de la teoría política y social ${ }^{174}$; por el contrario, sus contribuciones son más escasas y dispersas en cuestiones económicas ${ }^{175}$. Aun así, Francisco Suárez efectuó algunas consideraciones interesantes en esta última disciplina. Por un lado, impulsó el redescubrimiento de la teoría activa de los derechos naturales aplicada a la propiedad privada ${ }^{176}$, fortaleciendo la teoría de la libertad de la voluntad del insigne jesuita Luis de Molina ${ }^{177}$. Y, por otro lado, reflexionó acerca de un sistema tributario justo y equitativo, analizando el sistema fiscal de la época desde un punto de vista social, doctrinal y, por supuesto, moral ${ }^{178}$. La lectura y la interpretación de estas dos

173. Ibidem (ed. CSIC, vol. 16, 373).

174. M. Grice-HutChinson, El pensamiento económico en España cit., 134.

175. Ibidem, 135.

176. Juan de Lugo fue la única excepción que afirmó que la propiedad privada era de derecho natural, J. DE Lugo, De Fustitia et jure agitur, disp. 6, sec. 1, en Disputationes scholasticae et morales (ed. de Luis Vives, París, 1868) t. 5, 631-633, citado en N. San EMETERIO Martín, op. cit., 53-55.

177. M. N. Rothbard, Historia del pensamiento económico, vol. I (Unión Editorial, Madrid, 1999) 148.

178. F. GÓmEZ CAMACHO, Economía y filosofía moral cit., cap. 7, 293-307. 
materias económicas fueron analizadas por los doctores españoles de los siglos XVI-XVII según el marco de la ley natural ${ }^{179}$.

179. Agradecimientos: En primer lugar, dedico estas páginas al Profesor Ángel Luis González García, que falleció antes de la publicación de este número monográfico dedicado al centenario de Francisco Suárez (1617-2017). Asimismo, agradezco las sugerencias bibliográficas del Profesor Miguel Alfonso MartínezEchevarría y Ortega así como también las útiles recomendaciones a la primera versión de este artículo por uno de los revisores científicos de la revista Anuario Filosófico, las cuales han contribuido a mejorar su resultado final. Por supuesto, cualquier error u omisión es mío. 